\title{
Treatment of Keratocystic Odontogenic Tumors in Nevoid Basal Cell Carcinoma Syndrome
}

\author{
Hyun-Ho Ryu, Dong-Yoon Shin, Seok-Hwan Ryu, Taek-Woo Kim, \\ Jong-Bum Lee, Bok-Joo Kim, Chul-Hoon Kim \\ Division of Oral and Maxillofacial Surgery, Department of Dentistry, Dong-A University Medical Center
}

\begin{abstract}
Nevoid basal cell carcinoma syndrome (NBCCS) is inherited as an autosomal dominant trait with variable conditions, including multiple basal cell carcinoma, numerous keratocystic odontogenic tumors (KOTs) in the jaws, ectopic calcification of the falx cerebri, bifid ribs, macrocephaly, kyphoscoliosis, cleft palate, frontal and temporal bossing, mild ocular hypertelorism, mild mandibular prognathism, vertebral fusion, and so on. A 16-year-old boy visited the Dong-A University Medical Center, requiring diagnosis and treatment of multiple cystic lesions. He presented with many conditions related to NBCCS, including multiple KOTs, bifid rib, cleft lip, frontal bossing, mild ocular hypertelorism, and mild mandibular prognathism. No characteristic cutaneous manifestations (nevoid basal cell carcinoma) were observed in this patient. We report on a case of multiple KOTs associated with NBCCS with a review of the literature.
\end{abstract}

Key words: Basal cell nevus syndrome, Multiple keratocystic odontogenic tumors, Multiple odontogenic keratocysts

\section{Introduction}

Nevoid basal cell carcinoma syndrome (NBCCS) was first reported by Jarish in 1894; a detailed description of its features was reported in the 1960 s by Drs. Robert Gorlin and Robert Golz[1-4].

NBCCS presents with a broad range of clinical symptoms, including multiple basal cell carcinoma, numerous keratocystic odontogenic tumors (KOTs) in the jaws, ectopic calcification of the falx cerebri, palmar and/or pits, and so on; therefore, this multidisciplinary disorder constitutes a true challenge for medical specialists[5-9]. In particular, dentists may be the first to encounter and identify this syndrome when multiple cyst like radiolucencies are discovered on radiographs of the jaws[8,10-12].

This syndrome begins to appear early in life, usually after five years of age and before 30 years of age[9], and the average age for diagnosis of NBCCS is 13 years, while the average age for detection of basal cell carcinoma is 20 years[2,5]. Jaw cysts associated with this syndrome usually appear earlier in life than solitary KOTs, also earlier than other manifestations of this syndrome, and their recurrence is greater than that reported for solitary KOTs[9]. Histopathologically, the cysts of this syndrome are always odontogenic keratocysts or keratatogenic odontogenic tumors[13]. 

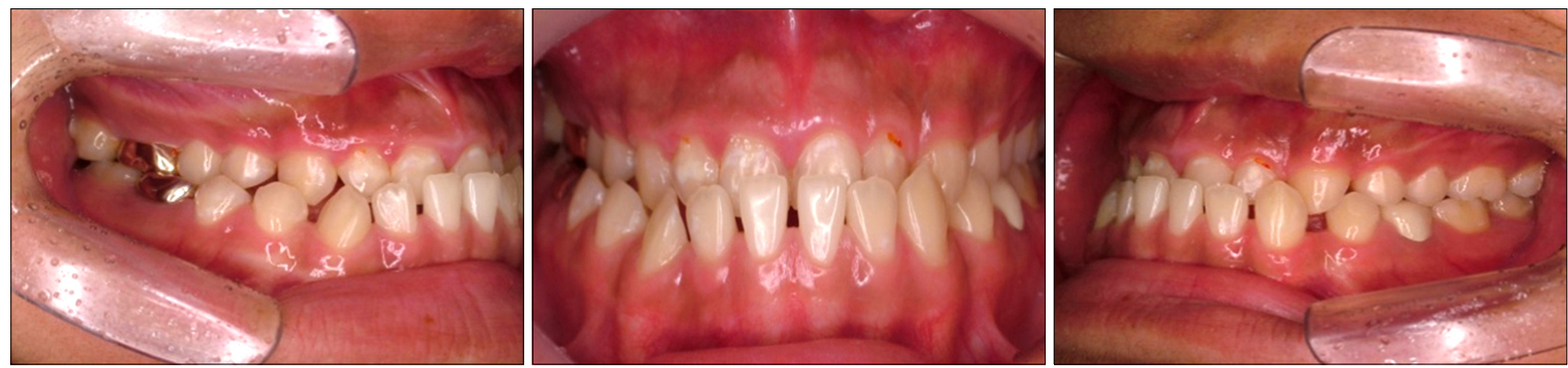

Fig. 1. Clinical photos. Intraoral photos.

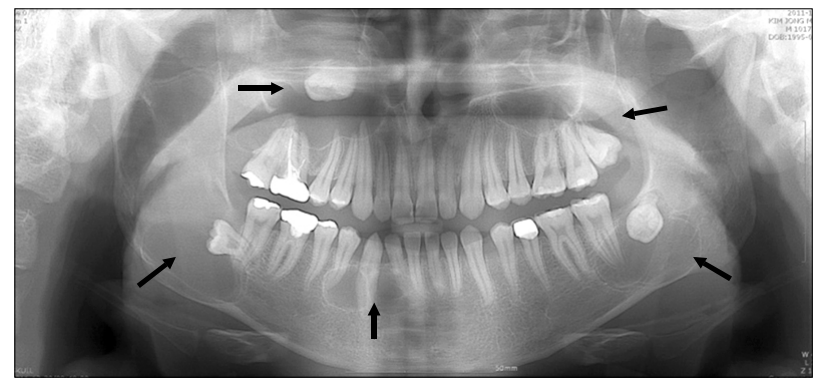

Fig. 2. Preoperative panoramic radiography (arrows: cystic lesions).

Considering the rarity of this syndrome, we report on a young subject affected by NBCCS. A review of the literature is also included.

\section{Case Report}

A 16-year-old boy, who had been diagnosed with multiple cysts of the jaws in another tertiary medical center, visited the Dong-A University Medical Center, requiring re-diagnosis and treatment for multiple cystic lesions. There were no subjective symptoms and a full body clinical examination revealed frontal bossing, unilateral cleft lip on the left side, ocular hypertelorism, and mild mandibular prognathism (Fig. 1). Panoramic radiography showed six large radiolucent lesions on bilateral posterior sites of maxilla and mandible involving third molars and the right madibular canine site (separately adjacent lesions) (Fig. 2). According to these findings, we suspected multiple jaw cysts associated with NBCCS and we took a skull posteroanterior (PA) view and chest radiography. Skull PA view showed no specific features. Chest PA radiograph showed two bifid formations of the right third rib and left fourth rib (Fig. 3).

Facial computed tomography showed bony expansion

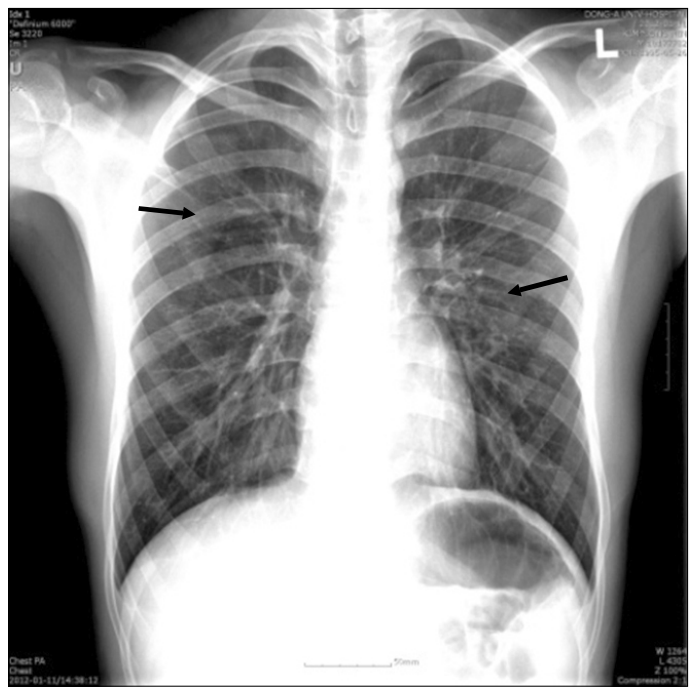

Fig. 3. Chest posteroanterior radiograph (arrows: bifid rib).

of the right maxillary sinus, left maxillary tuberosity, and right mandibluar ramus. Even the orbital wall of the right maxillary sinus was expanded and more than two thirds of the right mandibular ramus was occupied by cystic lesion. All third molars were involved to cystic lesions (Fig. 4). On the right mandibular canine site, two cysts were adjacent separately. Characteristic cutaneous manifestation (nevoid basal cell carcinoma) was not observed in this patient. In addition, his younger brother and mother did not show specific abnormalities.

The presence of minor and major criteria allowed the diagnosis of NBCCS. We had a plan to eliminate the cysts, including involved third molars, under general anesthesia, and performed cyst enucleation on the right maxillary sinus, left maxillary tuberosity, left mandibular third molar, and right mandibular cainine area, and marsupialization was performed on the right mandibular ramal area (Fig. 5).

According to the histopathologic features, the mass 


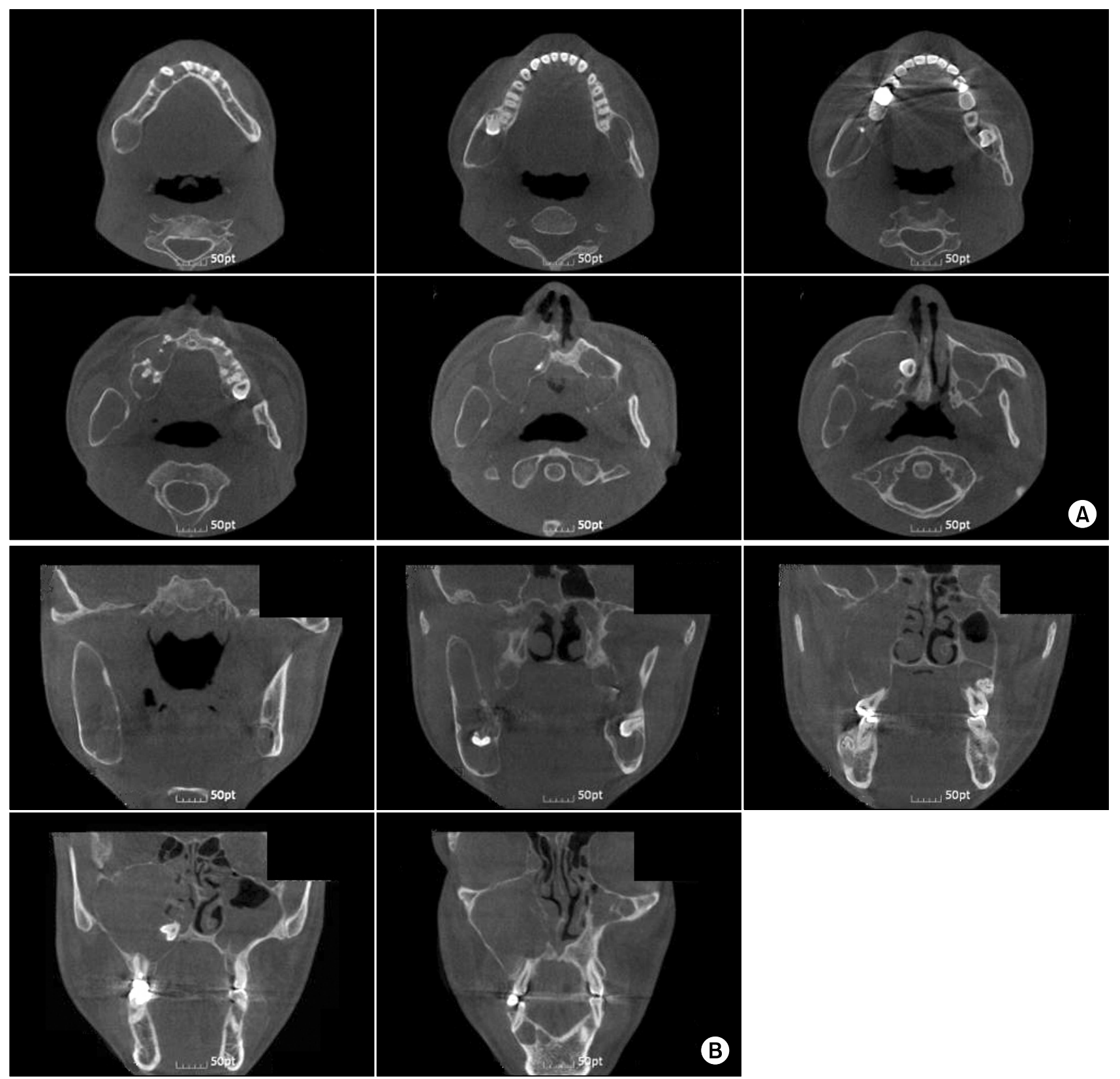

Fig. 4. Facial computed tomography. (A) Axial view. (B) Coronal view.

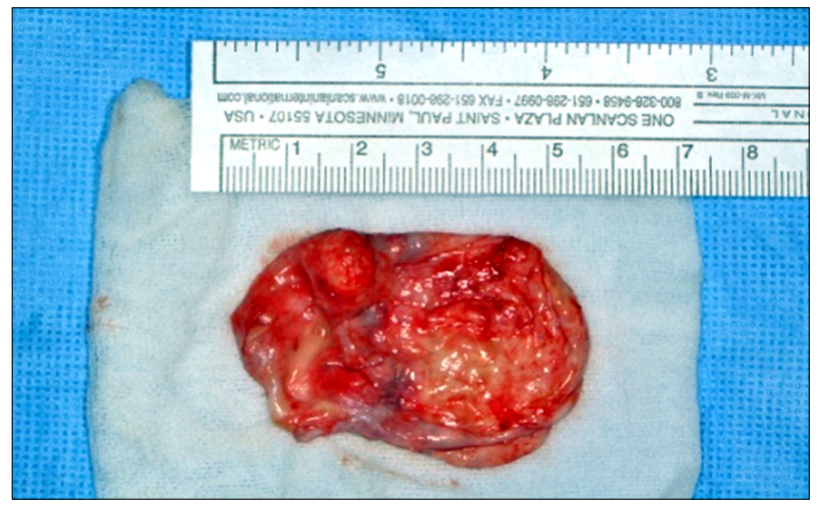

Fig. 5. Surgical specimen. showed a cystic appearance composed of a fibrocollagenous wall and the inner surface of the cyst was lined by wavy, corrugated epithelium (Fig. 6). On high magnification, squamous epithelium with parakeratosis composed of a palisaded layer of cuboidal or columnar epithelial cells and regimentation of the basal layer was identified, and the interface of epithelium and connective tissue was flat and the thin fibroma wall was devoid of any inflammatory infiltration. These histological features were consistent with KOT (Fig. 6). 

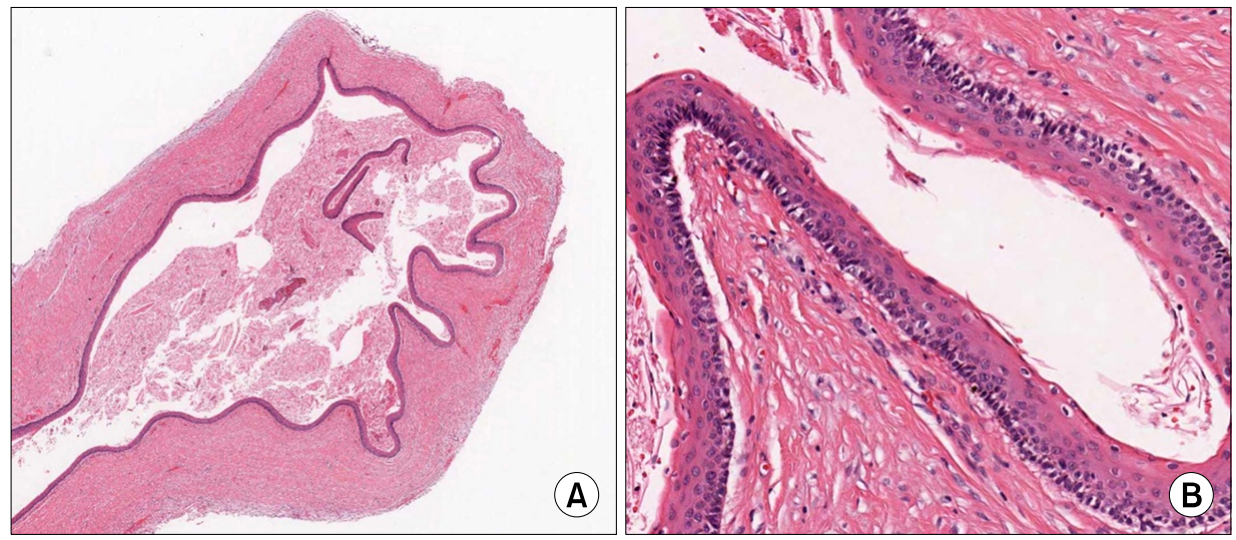

Fig. 6. Histopathologic view. (A) Histologic section $(\mathrm{H} \& \mathrm{E}, \times 20)$. (B) Histologic section (H\&E, $\times 200)$.
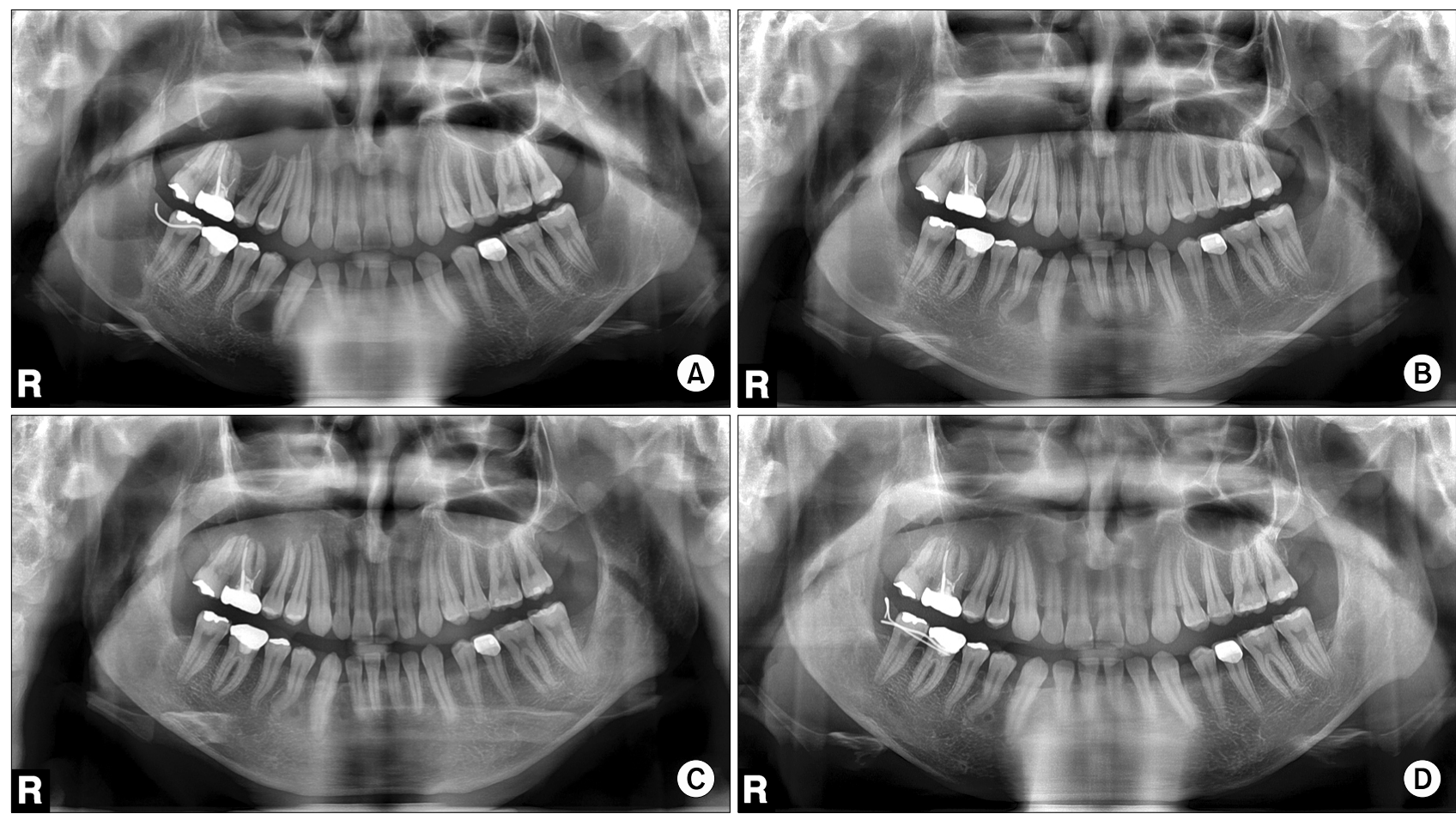

Fig. 7. Postoperative panoramic radiography. (A) One-month after operation. (B) Three-months after operation. (C) Six-months after operation. (D) Fourteen-months after operation.

Because of a higher recurrence rate of KOT in this syndrome, compared with solitary KOT, aggressive treatment is necessary. Yearly examination of the patient for evaluation of new and recurrent cysts is reasonable.

We performed follow-up panorama radiography at postoperative one, three, six, and 14 months (Fig. 7). In the present case, there was no evidence of recurrence of jaw cysts after 14 months.

\section{Discussion}

NBCCS is also referred to by several other names, including basal cell nevus syndrome (BCNS), basal cell carcinoma nevus syndrome, Gorlin syndrome, and Gorlin-Goltz syndrome[1,14]. In the scientific papers published in English, there are many synonyms for the syndrome, which often stem from its symptoms (Table 1)[15].

The assumed prevalence of the syndrome is 1:60,000; however, in several studies its values range from approximately 1:57,000 (in England) to 1:164,000 (in Australia) 
Table 1. Synonyms of nevoid basal cell carcinoma syndrome (NBCCS)

\begin{tabular}{ll}
\hline \multicolumn{1}{c}{ Designations of the NBCCS used in the scientific papers } \\
\hline Basal cell nevus carcinoma syndrome & Multiple basal-cell carcinoma syndrome \\
Epithelioma naevique multiple & Multiple basal-cell naevi syndrome \\
Fifth phakomatosis & Multiple hereditary cutaneomandibular polyoncosis \\
Gorlin syndrome & Multiple naevoid basal-cell carcinoma syndrome \\
Gorlin-Goltz syndrome & Naevous epitheliomatodes multiplex \\
Hereditary cutaneo-mandibular polyoncosis & Nevoid basal cell carcinoma epithelima-jaw cysts \\
Hermans-Grosfeld-Spaas-Valk syndrome & Ward syndrome II \\
\hline
\end{tabular}

Table 2. Clinical features of nevoid basal cell carcinoma syndrome

\begin{tabular}{lll}
\hline \multicolumn{1}{c}{$\geq 50 \%$ frequency } & \multicolumn{1}{c}{$15 \sim 49 \%$ frequency } & \multicolumn{1}{c}{ Medulloblastoma } \\
\hline Multiple basal carcinoma & Calcified ovarian fibromas & Meningioma \\
Keratocystic odontogenic cyst & Short fourth metacarpals & Lymphomesenteric cyst \\
Epidermal cyst of skin & Kyphoscoliosis or other vertebral anomalies & Cardiac fibroma \\
Palmar/plantar pits & Petus excavatum or carnatum & Fetal rhabdomyoma \\
Calcified falx cerebri & Stabismus (exotropia) & Marfanoid build \\
Enlarged head circumference & & Cleft lip and/or plate \\
Rib anomalities & & Hypogonadism in males \\
Mild ocular hypertelorism & & Mental retardation \\
Spina bifida occulta of cervical or thoracic vertebrae & & \\
\hline
\end{tabular}

to $1: 256,000$ (in Italy) to $1: 13,900,000$ (in Korea). The syndrome occurs with an equal frequency in men and women and in almost all ethnic groups, except for the Caucasian race, which is most often affected by it $[1,5,6]$.

The syndrome is characterized by multiple basal cell carcinoma, numerous KOTs in the jaws, ectopic calcification of the falx cerebri, and palmar and/or pits[5-9].

These traits are considered major clinical diagnostic criteria. The most notable and characteristic skin abnormality is nevoid basal cell carcinoma. Basal cell carcinoma is reported in approximately $76 \%$ of NBCCS cases, primarily affecting the face and back, followed by the chest[5]. In addition, $75 \%$ of patients affected by NBCCS often show multiple KOTs[7]. The dental clinician may be the first to encounter and identify this syndrome when multiple cyst like radiolucencies are discovered on radiographs of the jaws[8,10-12].

More than 100 minor criteria have been described for NBCCS; however, cardiac or ovarian fibroma, bifid ribs, macrocephaly, kyphoscoliosis, cleft palate, and meduloblastoma are the most frequent[5]. In addition, frontal and temporal bossing, mild ocular hypertelorism, mild mandibular prognathism, polydoctyly, and vertebral fusion can be included[1,5]. The Ellsworth-Howard test is used for differentiation of NBCCS from other disease status[8]. Gorlin listed the clinical features of the BCNS according to frequency (Table 2)[15].

Diagnosis of NBCCS may be difficult due to the numerous clinical features and different ages of onset for various traits of this syndrome. This syndrome begins to appear early in life, usually after five years of age, and before 30 years of age[9]. Average age for diagnosis is 13 years, while the average age for detection of basal cell carcinoma is 20 years[2,5].

NBCCS is a hereditary complex of abnormalities transmitted as an autosomal dominant trait with a high degree of penetrance and a variable expressivity characterized by several developmental defects and predisposition to cancer[16]. Although its occurrence among family members is an important diagnosing criteria, between 20\% and $40 \%$ of cases have been reported to result from a de novo mutation of the PTCH1 (9q22.3) gene[17,18]. According to the current state of knowledge, mutations of other genes such as Patched2 (PTCH2), Smoothened (SMO), and Sonic Hedgehog (SHH), also observed in relation to basal cell carcinoma and medulloblastoma[19,20], may exert a certain influence on the occurrence of the syndrome.

The authors report on a 16-year-old boy with NBCCS who showed multiple symptoms related to this syndrome. He presented with many conditions associated with NBCCS, including multiple KOTs, bifid rib, cleft lip, frontal bossing, a mild ocular hypertelorism, and mandibular 
prognathism. The presence of minor and major criteria allowed the diagnosis of NBCCS. Characteristic cutaneous manifestation (nevoid basal cell carcinoma) was not observed in this patient. The histopathologic features indicated that the mass was consistent with KOT.

A patient presenting with NBCCS requires multidisciplinary medical care. In addition, he should understand the nature of the disorder. Medical specialists are important in diagnosis and treatment of NBCCS because this syndrome presents with various conditions and traits. It is important to note that dentists may be the first to encounter and identify this syndrome when multiple cystic lesions are discovered on radiographs of the jaws.

\section{References}

1. Kiwilsza M, Sporniak-Tutak K. Gorlin-Goltz syndrome--a medical condition requiring a multidisciplinary approach. Med Sci Monit 2012;18:RA145-53.

2. Baliga SD, Rao SS. Nevoid-basal cell carcinoma syndrome: a case report and overview on diagnosis and management. J Maxillofac Oral Surg 2010;9:82-6.

3. Jawa DS, Sircar K, Somani R, Grover N, Jaidka S, Singh S. Gorlin-Goltz syndrome. J Oral Maxillofac Pathol 2009;13:89-92.

4. Karthiga KS, Sivapatha Sundharam B, Manikandan R. Nevoid basal cell carcinoma syndrome. Indian J Dent Res 2006;17: 50-3.

5. Ramaglia L, Morgese F, Pighetti M, Saviano R. Odontogenic keratocyst and uterus bicornis in nevoid basal cell carcinoma syndrome: case report and literature review. Oral Surg Oral Med Oral Pathol Oral Radiol Endod 2006;102:217-9.

6. Ahn SG, Lim YS, Kim DK, Kim SG, Lee SH, Yoon JH. Nevoid basal cell carcinoma syndrome: a retrospective analysis of 33 affected Korean individuals. Int J Oral Maxillofac Surg 2004; 33:458-62.

7. Mohtasham N, Nemati S, Jamshidi S, Habibi A, Johari M. Odontogenic keratocysts in Nevoid basal cell carcinoma syndrome: a case report. Cases J 2009;2:9399.
8. Wood Norman K, Goaz Paul W, editors. Differential diagnosis of oral and maxillofacial lesions. 5th ed. Philadelphia: Mosby; 1997. p.382-4.

9. White SC, Pharoach MJ, editors. Oral radiology, principles and interpretation. 5th ed. St. Louis: Mosby; 2004. p.397-8.

10. Li TJ, Browne RM, Matthews JB. Epithelial cell proliferation in odontogenic keratocysts: a comparative immunocytochemical study of Ki67 in simple, recurrent and basal cell naevus syndrome (BCNS)-associated lesions. J Oral Pathol Med 1995;24: 221-6.

11. el Murtadi A, Grehan D, Toner M, McCartan BE. Proliferating cell nuclear antigen staining in syndrome and nonsyndrome odontogenic keratocysts. Oral Surg Oral Med Oral Pathol Oral Radiol Endod 1996;81:217-20.

12. Neville BW, Damm DD, Allen CM, Bouquot JE. Odontogenic cyst and tumors. In: Kramer IPH, Pindborg JJ, editors. Oral \& maxillofacial pathology. 3rd ed. St. Louis: Saunders Elsevier; 2009. p. 683-91.

13. Regezi JA, Sciubba JJ, Jordan RCK. Cysts of the jaws and neck. In: Androulaki M, Johnson JT, editors. Oral pathology \& clinical pathologic correlation. 5th ed. Philadelphia: W B Saunders; 2008. p.245-9.

14. Tom WL, Hurley MY, Oliver DS, Shah MR, Bree AF. Features of basal cell carcinomas in basal cell nevus syndrome. Am J Med Genet A 2011;155:2098-104.

15. Gorlin RJ. Nevoid basal-cell carcinoma syndrome. Medicine (Baltimore) 1987;66:98-113.

16. Friedrich RE. Diagnosis and treatment of patients with nevoid basal cell carcinoma syndrome [Gorlin-Goltz syndrome (GGS)]. Anticancer Res 2007;27:1783-7.

17. Song YL, Zhang WF, Peng B, Wang CN, Wang Q, Bian Z. Germline mutations of the PTCH gene in families with odontogenic keratocysts and nevoid basal cell carcinoma syndrome. Tumour Biol 2006;27:175-80.

18. Acocella A, Sacco R, Bertolai R, Sacco N. Genetic and clinicopathologic aspects of Gorlin-Goltz syndrome (NBCCS): presentation of two case reports and literature review. Minerva Stomatol 2009;58:43-53.

19. Casaroto AR, Loures DC, Moreschi E, et al. Early diagnosis of Gorlin-Goltz syndrome: case report. Head Face Med 2011; $7: 2$.

20. Huang YF, Chen YJ, Yang HW. Nevoid basal cell carcinoma syndrome-case report and genetic study. J Dent Sci 2010;5: $166-70$. 